\title{
An initial investigation of Admissions Processes and their impact upon the Widening Access Agenda in Physiotherapy Education
}

\section{Project Outline:}

Physiotherapy has long been a profession dominated by female practitioners, despite increasing male entrants in recent years. Ethnic diversity within the profession is growing but the majority of students in physiotherapy education are white (CSP, 2015). In line with Widening Access strategies and following the response to the Francis Report, which called for improved screening of potential healthcare students, Cardiff University implemented changes to the application screening processes for physiotherapy admissions.

These changes included the method of scoring an application statement and the introduction of a panel interview. The purpose of this initial investigation is to investigate the impact these changes have had upon the resultant make-up of the cohort of students.

A retrospective review of the 2014 intake to Physiotherapy was undertaken. Details of the characteristics of all applicants were identified (Gender, Postcode, Local Education Authority, Socio-economic Grouping, Schooling, Disability, Ethnicity and Age) at each stage of the admissions process - initial application, those who were offered places, those who replied and those enrolled onto the respective courses.

\begin{tabular}{|c|c|c|c|c|}
\begin{tabular}{|c|c|c|} 
TABLE 1: \\
Percentages of \\
Applicants at each \\
stage.
\end{tabular} & \% Female & $\begin{array}{l}\text { \% Non-premium } \\
\text { postcode }\end{array}$ & $\begin{array}{l}\text { \% Low Socio- } \\
\text { economic group }\end{array}$ & \% Mature (>21yr) \\
\hline Applicants & 59 & 63 & - & 30 \\
\hline Offers & 72 & 66 & 13 & 26 \\
\hline Replies & 76 & 65 & 19 & 25 \\
\hline Enrolled & 76 & 63 & 22 & 26 \\
\hline
\end{tabular}

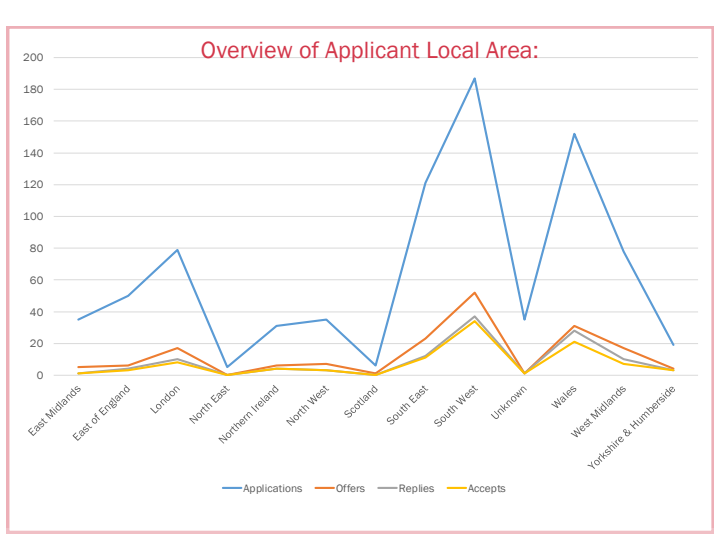

Overview of enrolled students to Cardiff Physiotherapy in 2014:
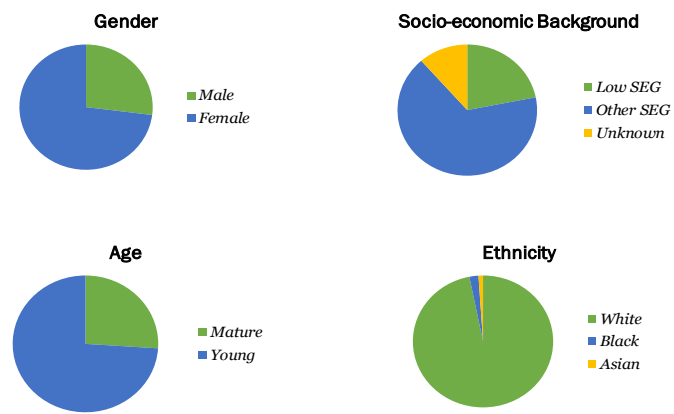

\section{Results:}

With respect to age, socio-economic grouping and postcode area, the percentages of each remained consistent through the screening out processes - e.g. $30 \%$ of total applicants and $26 \%$ of those enrolled were >21years old (Table 1).

Initially $59 \%$ of all applicants were female, but $76 \%$ of the resultant cohort were female. $97 \%$ of enrolled students were white and it has proved difficult to track this characteristic earlier in the process.

Disability disclosures were low and not mandatory therefore difficult to fully evaluate, however $8 \%$ of initial applicants and $5 \%$ of enrolled students did disclose a disability.

\section{Impact \& Implications:}

The majority of characteristics remained fairly static through each stage of the screening process, suggesting that the processes on the whole are nondiscriminatory. There is an anomaly with gender suggesting females are more likely to be successful. Reasons for this remain unclear, but may be related to actual academic achievement, different writing style within their personal statement, better performance at interview, or unconscious bias in the assessment/scoring process. Ethnic diversity is low at all stages of the admissions process, and lower than the UK higher education average for physiotherapy (CSP, 2015).

This initial investigation has demonstrated that there is a changing face of the physiotherapy profession at entry level, but that more could be done to improve participation within ethnic minority groups and to address the relatively poor performance by male applicants. Enhancing the diversity at undergraduate level would only serve to boost the profession's cultural competence as a whole, but efforts to reduce unconscious bias within education must be made. 